\title{
Histamine synthesis by respiratory tract micro-organisms: possible role in pathogenicity
}

\author{
J L DEVALIA, D GRADY,* Y HARMANYERI, S TABAQCHALI, * R J DAVIES \\ From the Departments of Respiratory Medicine and Medical Microbiology, ${ }^{*}$ St Bartholomew's Hospital, \\ London
}

SUMMARY Five bacterial species considered to be potential pathogens in acute exacerbations of chronic bronchitis, cystic fibrosis, and pneumonia-Branhamella catarrhalis, Haemophilus parainfluenzae, Pseudomonas aeruginosa, Staphylococcus aureus and Streptococcus pneumoniae-were evaluated for their potential to synthesise histamine in vitro. Bacterial species commonly isolated from infected sputum but generally not considered to be pathogenic-Enterobacteriacae, Neisseria pharyngis, coagulase negative staphylococci, $\alpha$-haemolytic streptococci, and Candida albicans-were similarly studied. Of the "pathogens", the Gram negative species $B$ catarrhalis, H parainfluenzae and Ps aeruginosa synthesised clinically important amounts of histamine; this was not the case for the Gram positive species $S$ aureus and $S$ pneumoniae. Of the "non-pathogenic" species, only the Enterobacteriacae, as a group, were found to synthesise clinically important amounts of histamine. These results show that some Gram negative bacteria, associated with acute exacerbations in respiratory infections, produce histamine and possibly other inflammatory mediators, which may contribute to their pathogenecity in the lower respiratory tract in vivo.

Although bacterial infections of the lower respiratory tract have long been associated with episodes of airflow limitation, their role in its development remains in dispute. The different bacteria predominating in different lung infections probably operate through similar mechanisms of pathogenesis, because both the symptoms and pattern of airflow limitation observed in these diseases are similar. Indeed, Haemophilus influenzae, Pseudomonas aeruginosa, and Streptococcus pneumoniae produce factors which damage and slow respiratory ciliary beat in vitro, ${ }^{1}$ and it is possible that this could lead to lowered mucus clearance, alveolar plugging, and increased bacterial colonisation of the lower respiratory tract in vivo. Several studies have shown that sputum collected during excerbations of infective lung conditions contain large amounts of histamine, ${ }^{2-4}$ and we have recently shown that respiratory tract bacteria are likely to be responsible for the synthesis of this histamine. $^{5}$ Indeed, our subsequent studies on the origin of histamine in the sputum have shown that $H$ influenzae can produce large amounts of histamine. ${ }^{6}$

We have now expanded our studies with $H$ influen$z a e$ and have investigated the histamine synthesising

Accepted for publication 12 January 1989 capacity of several other lower respiratory tract bacteria. We have looked at several isolates of Branhamella catarrhalis, Haemophilus parainfluenzae, Pseudomonas aerguinosa, Staphylococcus aureus and Streptococcus pneumoniae, which are considered to be potentially pathogenic in acute exacerbations of lower respiratory tract diseases. We also studied other micro-organisms isolated from purulent sputum but not normally considered to be contributing to the pathogenesis of the condition from which they were isolated (the "non-pathogenic" species). These included strains of the Enterobacteriacae group, Neisseria pharyngis, coagulase negative staphylococci, $\alpha$ haemolytic streptococci and the yeast Candida albicans.

\section{Material and methods}

Sputum samples from patients admitted to hospital with acute exacerbations of infective lung conditions-namely, chronic bronchitis, pneumonia, and cystic fibrosis - were used for isolation and study of various micro-organisms (table). All samples were collected in sterile containers and processed within two hours of collection, by mixing with an equal volume of Sputolysin (Oxoid Ltd) and incubation at room temperature for 15 minutes. After incubation the 
Table Nature and origin of micro-organisms studied

\begin{tabular}{ll}
\hline Species studied ( $n$ ) & Origin \\
\hline $\begin{array}{l}\text { Branhamella catarrhalis (8) } \\
\text { Haemophilus parainfluenzae (9) } \\
\text { Pseudomonas aeruginosa (11) }\end{array}$ & Chronic bronchitis \\
& Chronic bronchitis \\
Streptococcus pneumoniae (10) & Chronic bronchitis \\
Staphylococcus aureus (8) & Cystic fibrosis \\
& Pneumonia \\
Enterobacteriacae (12) & Chronic bronchitis \\
(Escherichia coli) & Chronic bronchitis \\
(Enterobacter species) & Cystic fibrosis \\
(Klebsiella species) & Chronic bronchitis \\
Coagulase negative staphylococci (11) & \\
Neisseria pharyngis (7) & \\
$\alpha$-haemolytis streptococcus (10) & Chronic bronchitis \\
Candida albicans (4) & Chronic bronchitis \\
\hline
\end{tabular}

samples were further mixed and cultured on horse blood agar and additional selective media, including chocolate, McConkey, and Sabouraud agar, incubated at $37^{\circ} \mathrm{C}$ in a $5 \%$ carbon dioxide in air atmosphere. Bacterial species considered to be either "pathogenic" or "non-pathogenic" were isolated and identified according to the following:

ISOLATION AND CULTURE OF BACTERIA NORMALLY CONSIDERED TO BE "PATHOGENIC" $B$ catarrhalis was identified according to colonial morphology, Gram stain, and ability to oxidise tetramethyl p-phenylenediamine. All isolates were stored on nutrient agar slopes at room temperature until required.

$H$ parainfluenzae was identified according to colonial morphology, Gram stain, resistance to Bacitracin $(0.1 \mathrm{U})$ and requirement for $\mathrm{V}$ factor (NAD). All isolates were stored on chocolate blood agar slopes at room temperature until required.

$P s$ aeruginosa was identified according to colonial morphology, pigment production, ability to grow on McConkey agar without fermenting lactose, ability to oxidise tetramethyl p-phenylenediamine and ability to grow at $42^{\circ} \mathrm{C}$. All isolates were stored on nutrient agar slopes at room temperature until required.

$S$ aureus was identified according to colonial morphology, Gram stain, and production of catalase and coagulase. All isolates were stored on nutrient agar slopes at room temperature until required.

$S$ pneumoniae was identified according to colonial morphology, Gram stain, $\alpha$-haemolysis of blood and its sensitivity to optochin $(5 \mu \mathrm{g})$. All the isolates were stored in Todd Hewitt broth (THB) with added glycerol and stored at $-70^{\circ} \mathrm{C}$ until required.

ISOLATION AND CULTURE OF MICRO-ORGANISMS NORMALLY CONSIDERED TO BE

"NON-PATHOGENIC"

Strains of the Enterobacteriacae group, including five isolates of Escherichia coli, three isolates of Klebsiella species, and four isolates of Enterobacter species were identified according to colonial morphology, Gram stain, ability to ferment lactose in McConkey agar and by the use of the API 20E biochemical test system (API Laboratory Products Ltd, Basingstoke). All isolates were stored on nutrient agar slopes at room temperature until required.

Coagulase negative staphylococci were identified according to colonial morphology, Gram stain, production of catalase, and failure to produce coagulase. All isolates were stored on nutrient agar slopes at room temperature until required.

$N$ pharyngis was identified according to colonial morphology, Gram stain, ability to oxidise tetramethyl p-phenylenediamine to iodophenol blue and ability to ferment glucose, maltose and sucrose. All the isolates were stored on nutrient agar slopes at room temperature until required.

Alpha-haemolytic streptococci were identified according to colonial morphology, Gram stain, $\alpha$-haemolysis of blood and its resistance to optochin $(5 \mathrm{~g})$. All the isolates were stored on blood agar slopes at room temperature until required.

Strains of the yeast Candida albicans isolated from sputum cultured on Sabouraud and horse blood agar plates, incubated at $30^{\circ} \mathrm{C}$, were also studied. These were identified according to colonial morphology, Gram stain, and germ tube production within two hours of incubation in serum broth. All the isolates were stored on Sabouraud agar slopes at room temperature until required.

After isolation and identification pure overnight cultures of all species were prepared by incubating a few colonies of each isolate, at $37^{\circ} \mathrm{C}$ in a $5 \%$ carbon dioxide in air atmosphere overnight, in either trypticase soy broth (TSB; BBL Microbiology Systems) or Todd Hewitt broth; (THB; Oxoid Ltd) supplemented with histidine $\left(1 \mathrm{~g}^{-1}\right)$ and pyridoxine phosphate $\left(5 \mathrm{mg} \mathrm{l}^{-1}\right)$. TSB was used in general, and in the case of $H$ parainfluenzae this was further supplemented with $5 \%$ Fildes extract (Oxoid Ltd) and in the case of $B$ catarrhalis with $1 \%$ horse serum. Pure cultures of $S$ pneumonia and $\alpha$-haemolytic streptococci were grown by incubation in THB.

Aliquots $(1.0 \mathrm{ml})$ of these "seed cultures" were inoculated into $20 \mathrm{ml}$ aliquots of supplemented TSB or THB and each culture incubated at $37^{\circ} \mathrm{C}$ for 48 hours with gentle agitation. Samples $(1.0 \mathrm{ml})$ were taken at 0 and 48 hours and stored at $-20^{\circ} \mathrm{C}$ before analysis for histamine. Subcultures of broth were made at $\mathbf{4 8}$ hours to check for growth and purity of the organism and any cultures found to be contaminated were discarded.

A growth curve was drawn for a representative of each species shown to produce histamine. Duplicate 

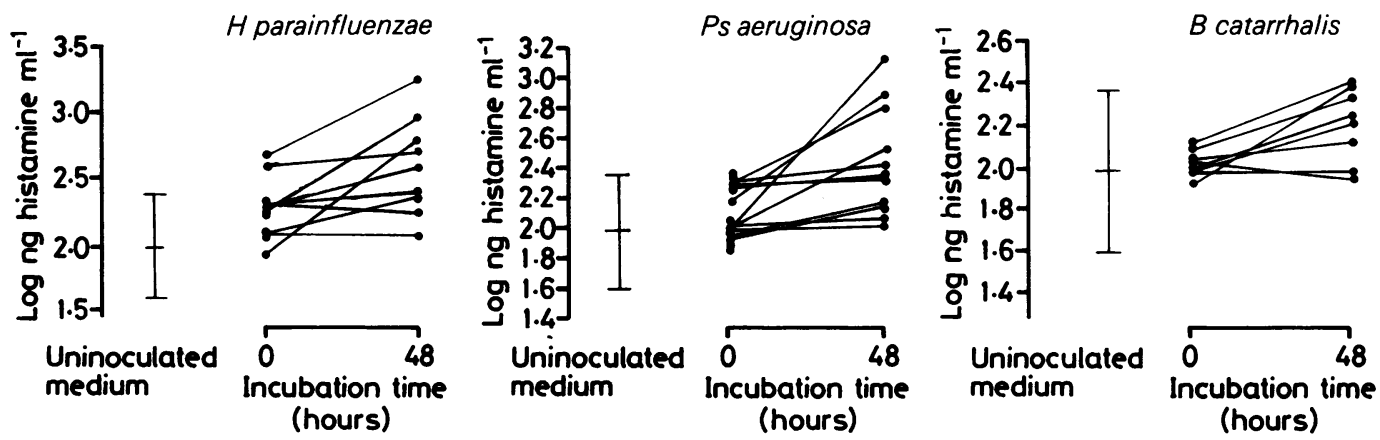

Fig 1 Histamine concentrations at 0 and 48 hours' incubation at $37^{\circ} \mathrm{C}$ for the Gram negative "pathogens". All species show significant increases in histamine after 48 hours $(p<0.02$ for $H$ parainfluenzae and Ps aeruginosa and $p<0.025$ for $B$ catarrhalis).

cultures were set up as described above and $1.0 \mathrm{ml}$ samples were taken at $0,2,4,6,8,24,31$ and 48 hours of incubation, for analysis of histamine and bacterial cell numbers.

Histamine in culture broth was measured by a reversed phase high performance liquid chromatographic technique (RP-HPLC) developed in our laboratory and described in detail elsewhere. ${ }^{7}$

The significance of differences in mean concentrations of histamine observed at the beginning and end of incubation for each species studied was established by the $t$ test.

\section{Results}

The histamine synthesising potential of the various bacterial species studied is shown in figs $1-3$. Of the

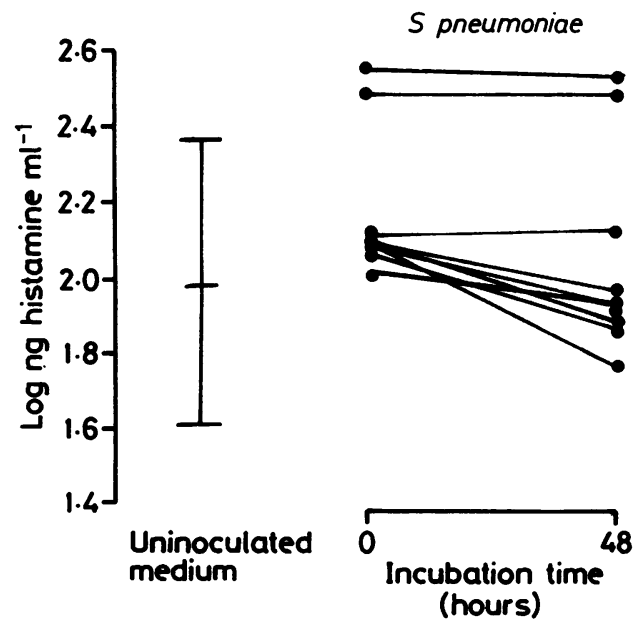

"pathogenic" species, only the Gram negative bacteria-namely $B$ catarrhalis, $H$ parainfluenzae, and $P S$ aeruginosa - synthesised histamine in vitro when cultured in histidine-enriched growth medium (fig 1). Although specific isolates of $\boldsymbol{H}$ parainfluenzae generated the highest amounts of histamine, and therefore the species as a whole seemed to be the most efficient histamine synthesiser of the three, analysis of histamine synthesis for the individual groups determined that this was not, in fact, the case. Both $H$ parainfluen$z a e$ and $P$ s aeuruginosa were equally efficient histamine synthesisers and showed a three-fold increase in histamine after incubation for $\mathbf{4 8}$ hours. In the case of $H$ parainfluenzae seven out of nine isolates produced significant increases in histamine and in the case of $P s$ aeruginosa eight out of 11 isolates produced significant increases in histamine $(p<0.02$ and $p<0.025$, respectively; geometric means, respectively, of 407.4

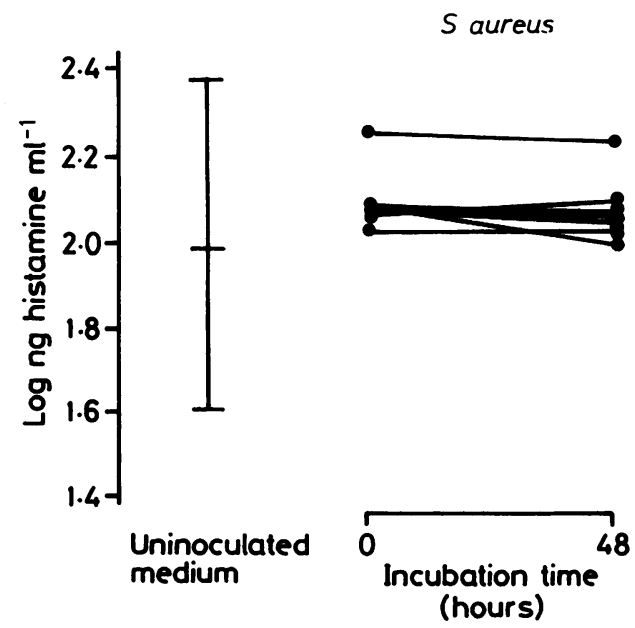

Fig 2 Histamine concentrations at 0 and 48 hours' incubation at $37^{\circ} \mathrm{C}$ for the Gram positive "pathogens". Neither $S$ aureus nor $S$ pneumoniae produced significant amounts of histamine after 48 hours. 


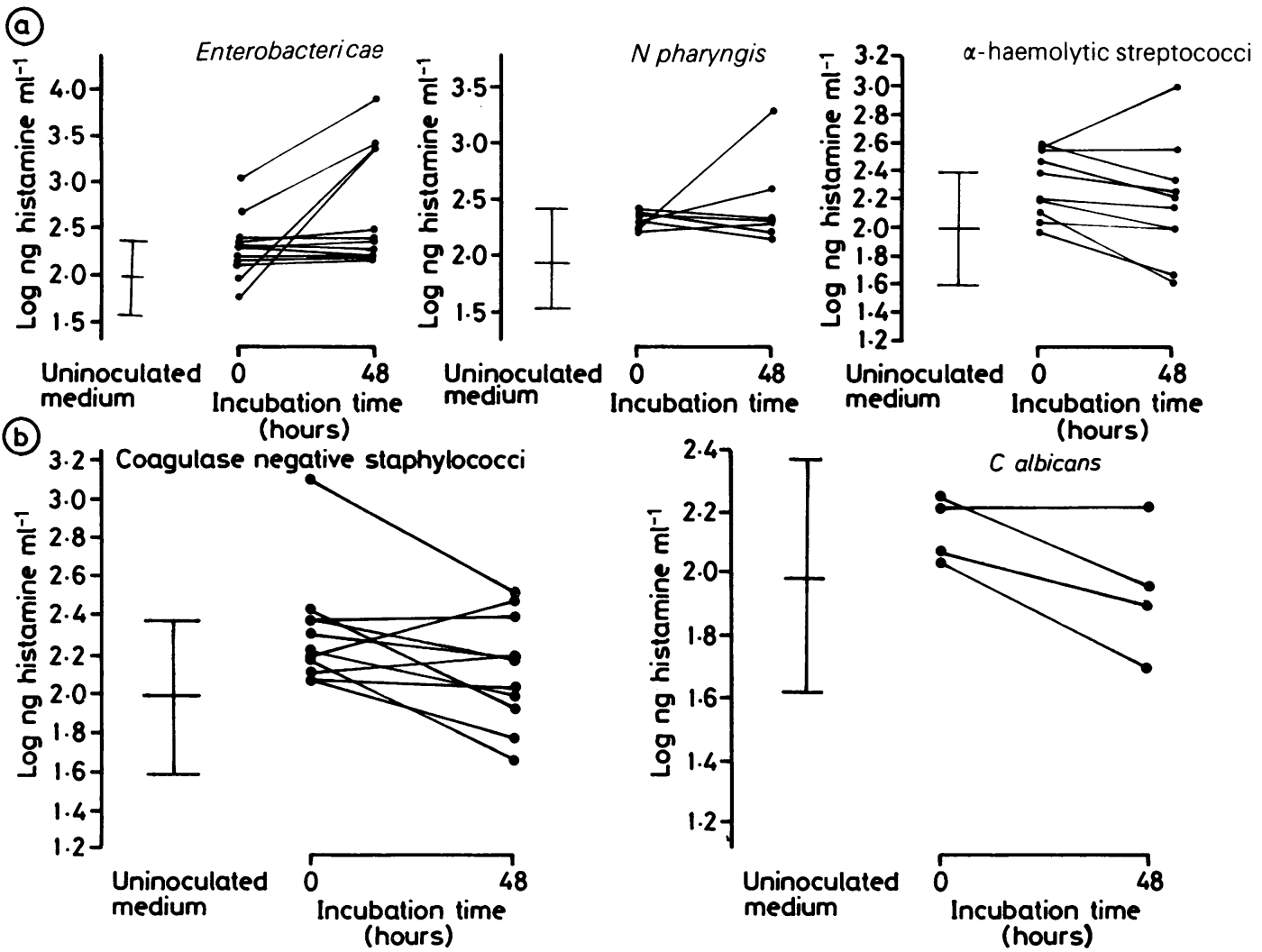

Figs $3 \mathrm{a}$ and b Histamine concentrations at 0 and 48 hours' incubation at $37^{\circ} \mathrm{C}$ for the "non-pathogens". Of these, only the Enterobacteriacae as a group produced significant amounts of histamine after 48 hours $(p<0.05)$.

(range $=309.0$ to 537.0 ) and 269.2 (range $=208.9$ to 346.7) $\mathrm{ng}$ histamine $\mathrm{ml}^{-1}$ by 48 hours' incubation, compared with geometric means of 190.5 (range $=158.5$ to 229.1 ) and 128.8 (range $=114.8$ to 144.5 ) ng histamine $\mathrm{ml}^{-1}$, at the beginning of incubation). In comparison, six out of eight isolates of $\boldsymbol{B}$ catarrhalis showed significant increases in histamine after incubation for 48 hours $(p<0.05)$, and on the whole these produced up to about a one and a half-fold increase in histamine (geometric mean of 162.2 (range $=141 \cdot 2$ to 186.2) $\mathrm{ng}$ histamine $\mathrm{ml}^{-1}$, by 48 hours' incubation, compared with a baseline level geometric mean of 104.7 (range $=100.0$ to 109.6$) \mathrm{ng}$ histamine $\mathrm{ml}^{-1}$ ).

Fig 2 shows the results for the Gram positive bacterial "pathogens",-namely, $S$ pneumoniae and $S$ aureus. Not a single isolate from either of these species synthesised histamine in vitro (geometric means, respectively, of 109.6 (range $=91.2$ to 131.8$)$ and 117.5 (range $=109.6$ to 125.9 ) $\mathrm{ng}$ histamine $\mathrm{ml}^{-1}$ by 48 hours' incubation, compared with geometric means of 147.9 (range $=128.8$ to 169.8 ) and 123.0 (range $=114.8$ to 131.8$) \mathrm{ng}$ histamine $\mathrm{ml}^{-1}$, at the beginning of incubation). Indeed, seven out of the 10 isolates of $S$ pneumoniae studied showed significantly lower concentrations of histamine at the end of the incubation period compared with the beginning of the incubation ( $p<0.01)$. Results for the histamine synthesising capacity of the organisms not considered to be contributing to the pathogenesis of the condition from which they were isolated are shown in figs $3 a$ and $b$. As was the case for the Gram positive "pathogens" most of the isolates in this category were generally not found to synthesise histamine in vitro (geometric means at 0 and 48 hours' incubation of 218.8 (range $=204.2$ to 234.4 ) and $263.0($ range $=204.2$ to 338.8$)$ ng histamine $\mathrm{ml}^{-1}$ for $N$ pharyngis; $204 \cdot 2$ (range $=173.8$ to $239 \cdot 9$ ) and 154.9 (range $=114.8$ to 208.9$)$ ng histamine $\mathrm{ml}^{-1}$ for $\alpha$-haemolytic streptococci; 204.2 (range $=165.9$ to 251.2 ) and 131.8 (range $=109.6$ to 158.5 ) ng histamine $\mathrm{ml}^{-1}$ for coagulase negative staphylococci; 138.0 (range 123.0 to 154.9 ) and $87 \cdot 1$ (range $=67.6$ to $112 \cdot 1$ ) ng histamine $\mathrm{ml}^{-1}$ for $C$ albicans). The Enterobacteriacae as a group did, however, synthesise significant amounts of histamine 
(p < 0.05; geometric means at 0 and 48 hours' incubation 208.9 (range $=166.0$ to 263.0) and 537.1 (range $=354.8$ to 812.8 ) $\mathrm{ng}$ histamine $\mathrm{ml}^{-1}$ ). Of the 12 isolates studied, only five synthesised histamine. A closer analysis of these showed that four were strains of $E$ coli, which produced a $4 \cdot 7$-fold increase in histamine (geometric mean 3580.5 ng histamine $\mathrm{ml}^{-1}$ by 48 hours' incubation, compared with $755.4 \mathrm{ng}$ histamine $\mathrm{ml}^{-1}$ at the beginning of incubation) and one was an Enterobacter cloacae strain which produced a 1.37-fold increase in histamine (339.0 ng histamine $\mathrm{ml}^{-1}$ by 48 hours' incubation compared with $248.0 \mathrm{ng}$ histamine $\mathrm{ml}^{-1}$ at beginning of incubation).

Fig 4 shows the relation between growth curve characteristics and histamine synthesis for the Gram negative bacterial "pathogens" and indicates that in the case of $H$ parainfluenzae maximal synthesis occurs during the stationary phase of the bacterial growth curve, as we have previously shown to be the case for $H$ influenzae. ${ }^{6}$ In the case of both Ps aeruginosa and $B$ catarrhalis, however, histamine synthesis seems to commence during the $\log$ phase and continue into the stationary phase of bacterial growth.

\section{Discussion}

The phenomenon of histamine synthesis by bacteria has long been recognised and generally associated with food spoilage and poisoning. ${ }^{8-11}$ Recently, we have shown that this phenomenon is not restricted solely to the putrefying bacteria and that respiratory tract bacteria are capable of generating large amounts of histamine. ${ }^{56}$ The findings of our present experiments confirm this and show that of the species tested, it is only the Gram negative bacteria which have this ability to synthesise histamine in vitro. This is an interesting finding in view of the fact that several Gram positive bacteria are known to contain histidine decarboxylase, the enzyme responsible for the conversion of histidine to histamine, and are therefore clearly capable of synthesising histamine. Strains of $S$ pneumoniae and Streptococcus pyogenes isolated from otitis media, ${ }^{12}$ have also been found to synthesise histamine in vitro. Several groups of authors have shown that environmental factors, such as $\mathrm{pH}$, have an important role in modifying either the activity or the synthesis of bacterial histidine decarboxylase. ${ }^{1314} \mathrm{In}$

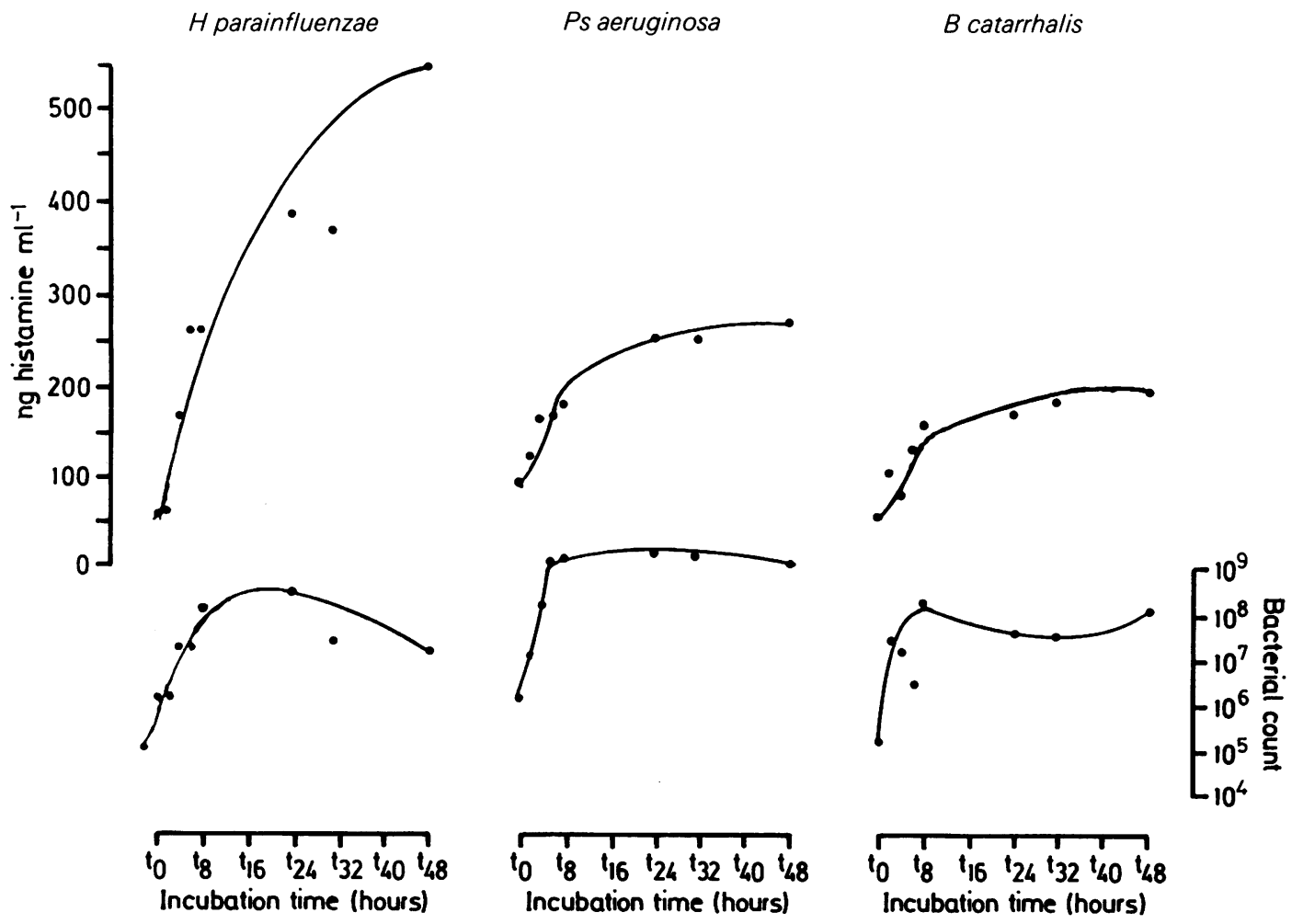

Fig 4 Relation between histamine synthesis and bacterial growth-curve characteristics for the Gram negative "pathogens". 
accordance with the findings of other authors, ${ }^{15}$ we found that the $\mathrm{pH}$ of sputum from infective lung diseases ranges from $\mathrm{pH} 6.9$ to 8.0 , and is clearly a range which will permit expression of considerable activity of this bacterial enzyme, even though for most bacteria the optimum $\mathrm{pH}$ is $5 \cdot 0-5 \cdot 5 .^{16}$ The influence of the environment alone, however, is unlikely to explain our findings for the Gram positive bacteria, because it is expected that the Gram negative bacteria studied would be similarly affected. It is more likely that the differences in the histamine synthesising capacity of the different organisms may be a result of the combination of both environmental factors and differences at the genetic level in these organisms. The latter may reflect either their ability or inability to synthesise histidine decarboxylase. Vanderslice et al recently cloned and determined the nucleotide sequence of the gene responsible for synthesis of prohistidine decarboxylase (the pro-enzyme which autoactivates to histidine decarboxylase), from both wild and mutant strains of Lactobacillus 30a, ${ }^{17}$ and they showed that the mutant strains do, indeed, have a different sequence from the one found in the wild type. These authors further showed that although both types produce prohistidine decarboxylase, the one found in the mutant strain cannot autoactivate itself unless specific $\mathrm{pH}$ changes are effected.

On this basis it is possible that the non-histamine producing species studied, whether "pathogenic" or "non-pathogenic", were either unable to synthesise prohistidine decarboxylase at all or else synthesised the form which could not autoactivate itself. Some of the Enterobacteriacae-namely, E coli and Enterobacter cloacae, however, did not conform to this general finding for the "non-pathogenic" species. Although these two species have previously been classified as being important causative "pathogens" in pneumoniae ${ }^{18}$ they are generally not considered to be pathogenic in chronic bronchitis. While these species clearly have the enzyme to synthesise histamine, in chronic bronchitis the growth of these species may be inhibited by other predominating bacterial species in vivo.

Recently Church et al showed that many whole bacterial species killed with formalin are capable of inducing non-IgE-dependent histamine release from human lung and tonsillar mast cells and that the Gram negative bacteria are generally more potent than the Gram positive bacteria in their ability to induce histamine release in vitro. ${ }^{19}$

Histamine has important biological effects on the lung, including smooth muscle contraction, stimulation of mucus secretion, and vagal afferent stimulation. Histamine has also been shown to increase pulmonary permeability in $\operatorname{man}^{20}$ and bronchial epithelial permeability in guinea pigs. ${ }^{21}$ Recently, White et al reviewed the role of histamine in asthma and suggested that histamine may also have a role in disruption of airway epithelium, ${ }^{22}$ which is thought to play a part in the induction of airway hyperreactivity. ${ }^{23}$ From the clinical viewpoint, it is feasible that histamine production by bacteria could contribute to airflow obstruction as a result of one or more of these actions. Histamine production may facilitate invasion and colonisation of tissue by bacteria as a consequence of epithelial disruption. Indeed, a recent study by Farley et al, ${ }^{24}$ using an experimental model of human nasopharyngeal tissue in organ culture, clearly showed that $\boldsymbol{H}$ influenzae attached selectively to non-ciliated epithelial cells and then invaded the tissue between epithelial cells after 12-14 hours of infection. These authors were not, however, able to elucidate the mechanism/s involved in the mucosal attachment, invasion, and colonisation by $H$ influenzae.

It may well be that a bacterium's ability to synthesise or induce the release of histamine and possibly other inflammatory mediators and compounds such as ciliotoxins ${ }^{1}$ aids colonisation and may be a reflection of its virulence in vivo.

We thank the British Lung Foundation, Asthma Research Council, Joint Research Board of St Bartholomew's Hospital, and Eli Lilly for financial support for this work. We also thank Mr Michael Poole (Gwynedd General Hospital, Bangor, Wales) and Dr Philip Mannion (Public Health Laboratory, Brighton) for providing some of the isolated strains of $B$ catarrhalis and $H$ parainfluenzae, and Miss Jean Hibbs (London Chest Hospital) for providing some $S$ aureus and $P$ s aeruginosa isolates.

\section{References}

1 Wilson R. Haemophilus influenzae in chronic and recurrent chest infections. Respiratory Diseases in Practice 1987;(Suppl 1):7.

2 Turnbull LS, Turnbull LW, Leitch AG, Crofton JW, Kay AB. Mediators of immediate-type hypersensitivity in sputum from patients with chronic bronchitis and asthma. Lancet 1977;i: 526-9.

3 Bryant DH, Pui A. Histamine content of sputum from patients with asthma and chronic bronchitis. Clin Allergy 1982;12: 19-27.

4 Moodley I, Zhong NS, Morgan DJR, Davies RJ. A comparison of the available methods for the measurement of histamine in sputum. Clin Allergy 1984;14:153-63.

5 Sheinman BD, Devalia JL, Crook SJ, Davies RJ. De novo synthesis of histamine in sputum and the effect of antibiotics. Agents and Actions 1985;17:449-53.

6 Sheinman BD, Devalia JL, Davies RJ, Crook SJ, Tabaqchali S. Synthesis of histamine by Haemophilus influenzae. $\mathrm{Br} \mathrm{Med} \mathrm{J}$ 1986;292:857-8.

7 Devalia JL, Sheinman BD, Davies RJ. Highly sensitive highperformance liquid chromatographic technique for the simultaneous measurement of histamine, 1-methylhistamine and other biogenic amines. J Chromatogr 1985;343:407-12.

8 Arnold SH, Brown WD. Histamine (?) toxicity from fish products. Adv Food Res 1978;24:113-54. 
9 Gilbert RJ, Hobbs G, Murray CK, Cruickshank JG, Young SEJ. Scombrotoxic fish poisoning: features of the first 50 incidents to be reported in Britain (1976-1979). Br Med J 1980;281:71-2.

10 Murray CK, Hobbs G. Scombrotoxin and scombrotoxin-like poisoning from canned fish. J Hyg (Camb) 1982;88:215-20.

11 Yoshinga DH, Frank HA. Histamine-producing bacteria in decomposing Skipjack Tuna (Katsuwonus pelamis). Appl Environ Microbiol 1982;44:447-52.

12 Brier GL, Bowsher RR, Black ER, Henry DP. Production of histamine by organisms associated with upper respiratory tract infections. Fed Proc 1985;44:1247.

13 Ienistea C. Bacterial production and destruction of histamine in foods, and food poisoning caused by histamine. Die Nahrung 1971;15:109-13.

14 Recsei PA, Snell EE. Prohistidine decarboxylase from Lactobacillus 30a. A new type of zymogen. Biochemistry 1973;12:365-71.

15 Ryley HC, Brogan TD. Variation in the composition of sputum in chronic chest diseases. Br J Exp Pathol 1968;49:625-33.

16 Beaven MA, Horakova Z, Severs WB. Bacterial histidine decarboxylase in rat stomach. Eur J Pharmacol 1970;11:233-40.

17 Vanderslice P, Copeland WC, Robertus JD. Cloning and nucleotide sequence of wild type and a mutant histidine decarboxylase from Lactobacillus 30a. $J$ Biol Chem 1986;261:15186-91.
18 Lerner AM, Federman MJ. Gram-negative bacillary pneumonia. J Infect Dis 1971;124:425-7.

19 Church MK, Norn S, Pao GJ-K, Holgate ST. Non-IgE-dependent bacteria-induced histamine release from human lung and tonsillar mast cells. Clin Allergy 1987;17:341-53.

20 Rees PJ, Shelton D, Chan TB, Eiser N, Clark TJ, Maisey MN. Effects of histamine on lung permeability in normal and asthmatic subjects. Thorax 1985;40:603-6.

21 Boucher RC, Ranga V, Pare D, Inoue S, Moroz LA, Hogg JC. Effect of histamine and methacholine on guinea-pig tracheal permeability to HRP. J Appl Physiol 1978;45:939-48.

22 White MV, Slater JE, Kaliner MA. Histamine and asthma. Am Rev Respir Dis 1987;135:1165-76.

23 Laitinen LA, Heino M, Laitinen A, Kava T, Haahtela T. Damage of the airway epithelium and bronchial reactivity in patients with asthma. Am Rev Respir Dis 1985;131:599-606.

24 Farley MM, Stephens DS, Mulks MH, et al. Pathogenesis of IgA I protease-producing and -nonproducing Haemophilus influenzae in human nasopharyngeal organ cultures. $J$ Infect Dis 1986;154:752-9.

Requests for reprints to: Dr J L Devalia, Department of Respiratory Medicine, St Bartholomew's Hospital, West Smithfield, London ECIA 7BE. England. 